\title{
O DIÁLOGO INSTITUCIONAL E AS TEORIAS DA DEMOCRACIA: CONTRIBUIÇÕES DO MODELO DELIBERATIVO PARA A ARTICULAÇÃO ENTRE PODERES NO BRASIL
}

THE INSTITUTIONAL DIALOGUE AND DEMOCRACY'S THEORIES: CONTRIBUTIONS OF THE DELIBERATIVE MODEL TO THE ARTICULATION BETWEEN POWERS IN BRASIL

Maria Valentina de Moraes

Doutoranda no Programa da Pós-Graduação em Direito - Mestrado e Doutorado da Universidade de Santa Cruz do Sul - UNISC, com bolsa PROSUC/CAPES. Mestre em Direito pelo Programa da Pós-Graduação em Direito - Mestrado e Doutorado da Universidade de Santa Cruz do Sul - UNISC.

Mônia Clarissa Hennig Leal

Pós-Doutorado na Ruprecht-KarlsUniversität Heidelberg (Alemanha) e Doutorado em Direito pela Universidade do Vale do Rio dos Sinos - Unisinos (com pesquisas realizadas junto à Ruprecht-KarlsUniversität Heidelberg, na Alemanha). Professora do Programa de Pós-Graduação em Direito - Mestrado e Doutorado da Universidade de Santa Cruz do Sul - UNISC.

\section{Resumo}

Atualmente, a crise das instituições democráticas e o protagonismo judicial questionam o modelo de democracia. Não se pode olvidar do importante debate promovido pelas teorias democráticas e a relação entre poderes delas emanados. partindo-se de uma lógica de articulação entre Poderes, por meio do diálogo, questiona-se: como o modelo de democracia deliberativo pode contribuir para uma melhor aplicabilidade da teoria dialógica no Brasil, por meio da argumentação e do debate?. Utiliza-se, para tanto, o método comparativo com revisão bibliográfica, consistente na pesquisa doutrinária, a fim de observar a relação que pode se estabelecer entre as teorias deliberativa e dialógica. Apresentam-se, em um primeiro momento, aspectos relativos às teorias da democracia, para se discutir, então, o modelo deliberativo de democracia e, por fim, a teoria do diálogo institucional e as contribuições da democracia deliberativa de Habermas para sua otimização. Pode-se concluir, assim, que a adoção 
de uma postura deliberativa pode contribuir para uma melhor articulação entre Poderes e, consequentemente, para a realização de um debate que considere os melhores argumentos e um procedimento racional de tomada de decisões visando à efetivação de direitos fundamentais.

Palavras-chave: Democracia deliberativa. Diálogo entre poderes. Teorias da democracia.

\begin{abstract}
Currently, the existent crisis of democratic institutions and the judicial protagonism questioned the existing model of democracy. Can not forget the important debate promoted by democratic theories and the relation between powers that arise from them. In this sense, using an articulation logic between powers through dialogue, it's been questioned: how the deliberative democratic model can contribute for a better application of dialogue theory in Brazil, using debate and argumentation?. It was used for such, the comparative method with bibliographic review, consisting in a bibliographic search, in order to observe the relation that can be established between deliberative theory and dialogic theory. It is presented, in a first moment, aspects relating to democratic theories, to be able to discuss the deliberative democratic model and, in the end, the institutional dialogue theory and the contributions of Habermas deliberative democracy for its optimization. Therefore, can be concluded, that the adoption of a deliberative posture can contribute for a better articulation/relation between powers and, consequently, for a debate realization that considers the best arguments and a racional process of decision making aiming the fundamental rights effectiveness.
\end{abstract}

Key-words: Deliberative Democracy. Dialogue between powers. Democracy's Theories.

\title{
1. CONSIDERAÇÕES INICIAIS
}

Os diferentes modelos de Estado absolutismo trouxeram consigo maior protagonismo de um poder do Estado: o Estado Liberal notadamente marcado por uma centralidade do Poder Legislativo - por meio de garantias legais e não intervenção estatal -, o Estado Social, com caráter interventivo e atenções voltadas à atuação do Poder Executivo e, por fim, o Estado Democrático de Direito, caracterizado pela garantia de direitos fundamentais e princípios assegurados constitucionalmente, marcado pelo protagonismo do Poder Judiciário, na condição de guardião da Constituição.

A democracia representativa, que acompanhou esses modelos de Estado 
brasileiro, consideradas as diferenças que se apresentam nesse processo em termos de América Latina e com exceção dos períodos ditatoriais vividos - sofre muitas críticas nos dias de hoje. Dentre elas, podem ser destacadas a forma indireta de representação pelo sistema de legendas e a inexistência de uma democracia para além do voto, especialmente diante da crise de representatividade que assola os Poderes eleitos democraticamente, seja em razão de escândalos de corrupção ou de fenômenos de ordem política (como as disputas políticas entre poderes e as constantes trocas de partidos entre candidatos) que colocam em xeque a legitimidade dos eleitos. Frente a todas essas questões, o protagonismo judicial decorrente especialmente do reconhecimento da centralidade da Constituição e a noção de efetividade dos direitos fundamentais, que conduzem à análise do Poder Judiciário uma série de questões, foi ganhando força, fazendo com que os limites de atuação do Poder Judiciário fossem cada vez mais questionados.

A relação entre os Poderes do Estado - Legislativo e Executivo com caráter representativo e Judiciário com caráter contramajoritário -, pautada no princípio da separação de poderes e pensada em outro contexto social, necessita, desse modo, ser revista. As teorias dialógicas ganham destaque nesse cenário, ao defenderem uma atuação dos Poderes pautada no diálogo e no debate, superando a ideia de uma separação de poderes estática.

Nesse sentido, utilizando-se do método comparativo com revisão bibliográfica, busca-se, no modelo de democracia deliberativo analisado e proposto por Habermas, um suporte mais propício à realização desse diálogo e ao envolvimento entre Poderes diante de uma melhor argumentação, das noções de consenso e das condições ideais de fala que the servem como base. Questiona-se, assim, como a democracia deliberativa pode contribuir para uma otimização da teoria dialógica e de uma relação entre poderes que tenha como finalidade a máxima efetivação de direitos fundamentais.

Inicialmente serão trazidos, no primeiro capítulo, aspectos presentes nas diferentes teorias da democracia, como o liberalismo democrático, a representação e a participação popular, para então, no segundo capítulo, abordar conceitos e características do modelo de democracia deliberativa, nas visões de Habermas e Ralws - e seus interlocutores. No último capítulo, são discutidas as teorias do diálogo institucional e como essas convergem em muitos pontos, favorecendo uma perspectiva dialógica e uma atuação cada vez melhor dos Poderes do Estado. 


\section{AS DIFERENTES TEORIAS DA DEMOCRACIA: DO LIBERALISMO À PARTICIPAÇÃO POPULAR}

A crise de legitimidade que paira sobre os Poderes Executivo e Legislativo faz com que muito se critique a democracia. Contudo, tal crítica direciona-se à mesma de forma geral e abstrata, sem que se discuta de forma mais aprofundada sobre os modelos de democracia existentes e sobre os mais diferentes fatores que sobre ela incidem, como os arranjos globais, as particularidades de cada sociedade e os elementos culturais que as compõem e a própria política. Muitas já foram as formas de democracia adotadas ao longo da história, com algumas características presentes em muitas delas, como, por exemplo, a vinculação ao ideal de "governo no povo", de maioria e à noção de debate público - em menor ou maior medida. Pode-se dizer, assim, que "embora a extensão dos Estados contemporâneos impeça a reunião de todos em praça pública, a contribuição da democracia grega consiste na ideia de que os assuntos públicos devem ser decididos pelo debate público" (SOUZA; SOUZA, 2017, p. 153).

Alves e Souza (2017, p. 13) referem àa relação existente, ainda, entre democracia, poder jurídico e poder político, analisando que "a democracia e a supremacia do direito pressupõem que o poder político tenha suas ações vinculadas ao poder jurídico, atuando em nome e nos limites do direito". Observam, todavia, que "quando o poder político ultrapassa os limites do poder jurídico, surge uma crise de legitimidade desse poder, que passa a atuar de forma contrária às normas constitucionais" (ALVES; SANTOS, 2017, p. 13), afetando também a democracia e gerando um inevitável descrédito nas instituições consideradas democráticas.

Um elemento que é muito presente e que pauta as mais diferentes teorias da democracia guarda relação com a soberania popular, pontuando Nino (1997, p. 133) que "la democracia no es sólo el gobierno para y del pueblo, sino también por el pueblo"1. Há, desse modo, uma relação que se estabelece entre a democracia e o povo como princípio e finalidade dessa e, assim sendo, as decisões tomadas pelo povo

\footnotetext{
${ }^{1}$ Apresenta o autor, ainda, diferentes questões que cercam a utilização da expressão "pueblo", que, "(inmortalizada en el famoso discurso de Lincoln en Gettysburg com el aditamiento de la cláusula ' para el pueblo') es una ficción si 'pueblo' es entendido en otros sentidos. Si 'pueblo' denota la totalidad de los individuos que componen una población relevante, la democracia no garantiza que el pueblo se gobierne a sí mismo. Esa frase 'del pueblo' se refire a la totalidad, pero 'por el pueblo' puede referirse sólo a la mayoría de ese grupo" (NINO, 1997, p. 136). Nesse sentido também interessante a leitura de MÜLLER, Fredrich (Friedrich). Quem é o povo?. 7. ed. São Paulo: Revista dos Tribunais, 2013.
}

Revista de Direitos Fundamentais \& Democracia, Curitiba, v. 25, n. 3, p. 32-48, set./dez. 2020 
representariam a vontade da sociedade, em um clara lógica de governo da maioria. Essa relação com a maioria apresenta uma tensão, ao menos em tese, entre democracia e direitos individuais identificados com grupos que se apresentam como minoritários como polos opostos nessa relação, sendo, entretanto, a concepção mais comum aquela que defende uma conexão entre esses direitos de minorias com a democracia (NOVAIS, 2006), a medida em que a democracia pressupõe também o respeito dos direitos daqueles que não se encontram dentro de grupos maioritários.

Tem-se que "lajustificación de la democracia basada em la soberania popular no reconoce el contrapeso que le opone a la democracia el reconocimiento de los derechosindividuales", reforçando uma lógica de maioria e exclusão da vontade das minorias. (NINO, 1997, p. 137). Assim, "como sostiene Rousseau, ladecisión de pueblo no puede nunca ir en contra los derechos de los individuos", sendo imprescindível em uma democracia o respeito a esses, os quais caracterizam-se, como sustenta Dworkin, como trunfos contra a maioria. Em um Estado Democrático de Direito não há como sustentar uma democracia que permita violações aos direitos individuais - sendo, inclusive, nesse sentido a atribuição de um caráter contramajoritário ao Poder Judiciário, como órgão não eleito e responsável, ao menos em tese, pela proteção de direitos.

Dentre as teorias da democracia, a maior preocupação com os direitos individuais esteve presente nas teorias liberais, as quais defendiam decisões em sociedade, mas reservavam ao indivíduo um poder de decisão sobre determinadas questões. Mill (1986), nesse sentido, sustenta que as questões que envolvam a sociedade devem ser decididas por ela enquanto as que se referem à esfera individual devem ser tomadas exclusivamente pelo particular, utilizando como um critério para essa esfera individual a não afetação ou não ocorrência de prejuízo de terceiros com essas escolhas. O posicionamento defendido por Stuart Mill é analisado, no contexto em que fora pensado, por Nino (1997, p. 139), para quem essa visão da democracia "fue central en el movimiento antifederalista durante el período de discusión sobre la Constitución de Estados Unidos y es importante hoy en el movimiento neorrepublicanista dentro del derecho constitucional".

Embora o indivíduo detenha sua esfera de liberdade, não pode atuar de forma a perdê-la ou a acarretar prejuízos aos demais, existindo um direito social de se esperar que os indivíduos ajam de determinada forma e, sempre que sua ação atinja aos demais, existirão sanções para tanto (MILL, 1986). Defende, ainda, a possibilidade 
de intervenções do Estado quando a finalidade for ajudar os indivíduos ou mesmo fazer circular informações (MILL, 1986). Uma das críticas às teorias liberais e, em especial ao seu viés utilitarista, guarda relação com um ideário de vontade geral que não existiria de fato, sendo referida vontade geral contaminada pelas mais diversas influências (SCHUMPETER, 1961).

A preocupação com a manipulação dos interesses da sociedade é presente na obra de Schumpeter - o qual critica, por exemplo, a democracia direta por estar estritamente relacionada ao escrutínio, sem outras formas de participação que permitam aferir os interesses populares (SCHUMPETER, 1961). Held (1987, p. 255) traça, ainda, outra crítica às teorias liberais, entendendo que:

\begin{abstract}
os problemas são, em resumo, duplos: a estrutura da sociedade civil [...] incompreendida ou endossada pelos vários modelos democráticos liberais não cria condições para votos iguais, participação efetiva, compreensão política adequada e controle igualitário da agenda política, enquanto que a estrutura do Estado democrático liberal [...] não cria uma força organizacional que possa adequadamente regular os centros de poder "civil". (HELD, 1987, p. 255)
\end{abstract}

Haveria, portanto, falhas nos modelos liberais que comprometeriam o caráter democrático que se busca nas decisões. Utilizando-se de lógica diversa, Schumpeter (1961, p. 291) defende que "a democracia é um método político, isto é, certo tipo de arranjo institucional para chegar a uma decisão política (legislativa ouadministrativa) e, por isso mesmo, incapaz de ser um fim em si mesmo", ressaltando, inclusive, no fato de que em muitos regimes ditatoriais se utilizou de um método democrático sem que, conjuntamente, a substância possuísse também um caráter democrático (SCHUMPETER, 1961).

Desacreditando em uma vontade geral genuína e defendendo, então, um modelo representativo de democracia, Schumpeter (1961, p. 314) analisa que "na análise dos processos políticos, por conseguinte, descobrimos não uma vontade genuína, mas artificialmente fabricada", afetada por influências que não se sustentam ao longo do tempo. Desse modo, o principal problema das teorias democráticas reside na presunção de uma vontade do povo comum e manifesta, que será determinante para a atuação dos representantes escolhidos, apresentando a teoria clássica essa dificuldade em virtude da vontade do povo já ter servido aos interesses de governos não democráticos (SCHUMPETER, 1961).Nino (1997, p. 184) concebe que "larepresentación es, en el mejor de los casos, un mal necesario", pois, em termos de procedimento técnico a existência de intermediários seria benéfica, contudo, seria 
afetada no que toca aos interesses dos representados e os conflitos existentes (NINO, 1997).

No que se refere às teorias participativas, a noção de disseminação de informações também encontra-se presente, se mostrando necessário, para uma efetiva participação, o conhecimento sobre os reflexos das decisões. para que esses processos de efetiva participação ocorram, a informação - e a forma como ela circula é fundamental, devendo ser trabalhada a lógica de uma ligação entre grupos e não de subordinação ou autoridade, mas uma coordenação entre grupos (PATEMAN, 1992)2. Para que a participação ocorra de fato, os indivíduos precisam estar cientes quanto as questões envolvidas, estarem devidamente informados sobre os fatos, efeitos e consequências das decisões (PATEMAN, 1992).

Utilizando-se do exemplo das decisões tomadas de forma democrática em empresas - e traçando uma distinção entre participação e pseudoparticipação Pateman (1992) salienta a necessidade de conhecimento sobre o que se decide, exercendo a educação um papel essencial na análise da autora, "ou seja, os empregados precisam estar de possa das devidas informações sobre as quais possam basear sua decisão". Há que se considerar, contudo, que, embora a democracia participativa "inquestionavelmente, represente um avanço [...], o modelo deixa várias questões fundamentais sem resposta, inclusive como as condições de sua própria existência podem ser adequadamente asseguradas" (HELD, 1987, p. 253).

Diferentes impactos incidem sobre os modelos de democracia, como, por exemplo, no que se refere ao tamanho de um território - como o tempo de participação e de atenção dos representantes aos participantes -, sendo a participação mais efetiva em territórios muito menores (DAHL, 2001). Há que referir, entretanto, importantes exemplos de participação democrática no Brasil, como o orçamento participativo e os Conselhos Municipais, em nível local, e as Conferências e Conselhos Nacionais de Políticas Públicas, em nível federal, apresentando-se como interessantes exemplos de inovações democráticas mesmo em grandes territórios (LATINNO, https://www.latinno.net/pt/country/brazil/).

Assim, tanto a democracia participativa quanto a democracia deliberativa tem como problema central a efetividade das participações da sociedade, contudo, há na democracia deliberativa aspectos mais teóricos e na participativa outros mais

2 Observa-se que a autora trabalha com as teorias participativas partindo da relação entre grupos que se desenvolve em ambientes de trabalho e em sociedade.

Revista de Direitos Fundamentais \& Democracia, Curitiba, v. 25, n. 3, p. 32-48, set./dez. 2020 
relacionados a sua aplicabilidade (LEAL, 2011). Analisam-se, então, os modelos deliberativos de democracia e as críticas aos mesmos de forma a compreender como estes colaboram para a promoção de um diálogo entre os Poderes do Estado.

\section{DEMOCRACIA DELIBERATIVA: TENTATIVA DE HARMONIZAÇÃO (harmonização) ENTRE TEORIAS LIBERAIS E REPUBLICANAS}

As diferentes teorias da democracia possuem suas particularidades e, também, falhas, não existindo um modelo de democracia geral, aplicável a todas as sociedades em qualquer período da história. A democracia deliberativa surge com "la pretensión de armonizar las dos grandes tradiciones teóricas modernas de la democracia existentes: la democracia liberal y la democracia republicana, y [...] reivindica el papel de la deliberación como método de 'toma de decisiones"' (MÁRMOL, 2001, p. 163, grifado no original). Muitas são as teorias deliberativas pensadas, todavia, "se pueden clasificar grosso modo en dos escuelas principales, la primera de ellas es ampliamente influida por John Rawls, y por JürgenHabermas la segunda" (MOUFFE, 2003, não paginado, grifado no original). De uma forma geral:

\footnotetext{
podemos definir a democracia deliberativa como uma forma de governo na qual cidadãos livres e iguais (e seus representantes) justificam suas decisões, em um processo no qual apresentam uns aos outros motivos que são mutuamente aceitos e geralmente acessíveis, com o objetivo de atingir conclusões que vinculem no presente todos os cidadãos, mas que possibilitam uma discussao futura (GUTMANN; THOMPSON, 2007, p. 23).
}

Os dois autores buscam uma reaproximação com o liberalismo e, sobretudo, entendem que a produção de acordos tem o condão de garantir o futuro de instituições liberais democráticas, contudo, nem Habermas nem Rawls trouxeram soluções quando a harmonização entre liberalismo e democracia (MOUFFE, 2003). Nino (1997, p. 160) traz um apanhado das diferenças entre as teorias de Habermas e Ralws (Rawls), salientando que:

\footnotetext{
Habermas coincida con Rawls en que hay presupuestos formales, como el de imparcialidad, que son decisivos para otorgar validez a los princípios morales. Sin embargo, mientras para Rawls estos son presupuestos formales de un razonamiento moral monológico, para Habermas son reglas de una práctica social del discurso intersubjetivo. Para Rawls, la validez de los principios morales está dada por la satifacción de requerimiento de imparcialidad. Habermas, por otro lado, requiere un consenso de facto para ser constituido a través del empleo de la regla de imparcialidad. Finalmente, mientras Rawls parece pensar que una puede alcanzar la conclusión de que un principio moral
} 
el válido sólo por medio de le reflexión individual - aunque la discusión puede desempeñar un papel auxiliar -, Habermas claramente sostiene que este es imposible. Para Habermas, sólo la discusión colectiva, "en la búsqueda cooperativa de la verdad", es una forma confiable de acceder al conocimiento moral.

O procedimento deliberativo defendido por Habermas visa, assim, a produção de decisões corretas, contudo, não pode garantir esse resultado, apenas estabelecer condições para que o mesmo ocorra da melhor forma e, ainda, fornecer maiores informações aos participantes, permitindo que esses contraponham as informações existentes (MÁRMOL, 2001). Esse procedimento argumentativo não garante que as opiniões sejam, de fato, imparciais, mas exige que assim pareçam em razão da necessidade de uma justificação e argumentação que sustentem a opinião (MÁRMOL, 2001).O procedimento correto permite um controle argumentativo ao menos no que se refere à exteriorização dos argumentos utilizados, momento em que os mesmos serão confrontados, garantindo a racionalidade argumentativa que sustenta o autor.

Para Habermas (2007, p. 269), no modelo em que propõe "a diferença decisiva reside na compreensão do papel que cabe ao processo democrático" em relação ao estabelecido nos modelos liberais e republicanos. A formação de acordos também ocorre por motivações diferentes nos dois modelos: no modelo liberal os acordos são fundamentados em princípios liberais e guiados por interesses, já no modelo republicano há um "auto-entendimento ético", existindo um processo de discussões para a tomada de decisão e formação da vontade (HABERMAS, 2007).

Para que um modelo seja considerado, em seu procedimento, democrático, não é suficiente que sejam levados em conta os interesses de todos os envolvidos, devendo existir um poder comunicativo e estarem definidas as condições para que haja a formação de um consentimento livre, com imparcialidade moral (MOUFFE, 2003).Somente quando garantidas essas condições, observa Mouffe (2003, não paginado) que "entonces puede uno estar seguro de que el consenso que se obtiene es racional y no um mero acuerdo", ressaltado a diferença entendida por Habermas quanto ao consenso buscado e a formação dos mais diferentes tipos de acordo. Para Habermas se mostra necessário que as interações comunicativas permitam que os participantes conheçam os argumentos e, tomando-os em conta, argumentem a favor ou contra os mesmos, buscando assim obter um consenso sobre estes (NINO,1997).

O modelo Habermasiano, conhecido pelo seu viés procedimental, volta sua análise, justamente, para o estabelecimento de um procedimento que permita que as 
decisões sejam pautadas na racionalidade comunicativa, enquanto o modelo proposto por Rawls possui cunho muito mais substancial preocupado com o conteúdo da decisão a ser gerada de forma deliberativa, não destinando tanto sua análise ao procedimento. Uma das críticas a essa abordagem procedimental guarda relação com a impossibilidade de se ter uma separação efetiva entre o procedimento e a substância, não existindo procedimentos totalmente neutros, como quer Habermas, ao separar procedimental e substancial, moral e ético (MOUFFE, 2003). Observa Mouffe (2003, não paginado, grifado no original) que:

\begin{abstract}
para los habermasianos, la garantía de que el proceso de deliberación tiene resultados razonables depende de la medida en que cumpla la condición del <<discurso ideal >>: cuanto más igual e imparcial, más abierto será el proceso, y cuanto menos coaccionados estén los participantes y más dispuestos a dejarse guiar por la fuerza del mejor argumento, tanto más probable será que los intereses verdaderamente generalizables sean aceptados por todos aquellos a quienes afecta de manera relevante.
\end{abstract}

A democracia deliberativa como um todo tem sofrido críticas em razão da necessidade de comportamentos ideias, sendo de difícil aplicabilidade prática, embora possua uma boa estrutura teórica. A problemática central dos modelos deliberativos se encontra na dificuldade em encontrar mecanismos que permitam uma deliberação ampla, compartilhada de forma qualitativa e quantitativa, de acordo com os pressupostos estabelecidos (LEAL, 2011). Como coloca Mármol (2001, p. 180), "se ha venido criticando a los defensores de la democracia deliberativa por no presentar propuestas concretas de diseño institucional", que permitam a articulação das propostas sustentadas nesse modelo democrático e, consequentemente, eventual utilização prática das mesmas.

Contudo, pode-se dizer que "en los últimos años, los defensores de la DD [democracia deliberativa] han intentado paliar esta carencia presentando algunas propuestas, es cierto que falta todavía un trabajo más detallado en este ámbito" (MÁRMOL, 2001, p.180). Entretanto, embora a sua aplicação completa ainda encontre muitos obstáculos diante do caráter ideal que lhe acompanha, a adoção de uma lógica deliberativa em muito contribui para o processo dialógico entre Poderes do Estado. A solução, no que se refere às instituições democráticas, está, assim, na substituição de uma lógica de meios e fins para uma lógica deliberativa e comunicativa (MOUFFE, 2003).

Como salienta Nino (1997, p. 143), “un diálogo dificilmente pueda progresar sí 
los participantes se limitan a describirlo que ya saben desde el comienzo: que sus interesses son diferentes y que posiblemente se encuentran em conflicto", sendo necessária uma articulação pautada na boa-fé dos envolvidos e que tenha como objetivo o efetivo debate acerca das melhores decisões a serem tomadas. Passa-se, então, a discussão sobre a teoria do diálogo entre poderes, buscando compreender em que pontos a lógica deliberativa contribui para sua melhor aplicabilidade.

\section{O DIÁLOGO ENTRE PODERES E OS PROCESSOS DELIBERATIVOS: CONTRIBUIÇÕES ENTRE AS TEORIAS DIALÓGICA E DELIBERATIVA}

A formação de acordos racionais é pautada, para Habermas, em três tipos de discursos: um pragmático, um ético e um moral, denotando um diálogo necessário que se volta ao consenso e que abandone progressivamente posturas egocêntricas (HABERMAS, apud., LEAL, 2011). Essa superação de posturas notadamente marcadas pela supremacia e pelo egocentrismo é uma característica também das teorias dialógicas, para as quais "o sentido futuro da Constituição é resultado de uma complexa dinâmica de interação entre os Poderes Públicos, e entre eles e a sociedade civil. Essa resposta apresenta a vantagem de reconhecer a falibilidade de todas as instituições políticas", contrariando tanto as doutrinas de supremacia judicial como de supremacia parlamentar (BRANDÃO, 2012, p. 208).

As teorias que defendem o diálogo institucional, como analisa Mendes (2008, p. 98), "têm em comum e [...] contrastam com teorias da última palavra. Dois são os seus principais denominadores comuns: a recusa da visão juricêntrica e do monopólio judicial na interpretação da constituição". A adoção de uma lógica deliberativa pelos Poderes do Estado permite que, superando uma relação de supremacia, "quando estes deliberam, eles podem expandir seu conhecimento, incluindo tanto seu autoconhecimento quanto o seu entendimento coletivo acerca do que servirá melhor aos seus concidadãos" (GUTMANN; THOMPSON, 2007, p. 28). A interpretação constitucional não está centrada - ou não deveria estar - apenas nas mãos do Poder Judiciário, "rather, constitutional interpretation is an elaborate discussion between judges and the body politic" (FRIEDMAN, 1993, p. 653).

O diálogo entre Poderes pressupõe, desse modo, uma interação entre Executivo, Legislativo e Judiciário, devendo "haber una reflexión acerca de la decisión judicial por parte del gobierno y se debió adoptar una resolución respecto de como 
reaccionar frente a ella (HOGG; BUSHEL, 2014, não paginado). Nesse sentido Tushnet (2014, não paginado) propõe uma revisão judicial dialógica, entendendo que essa "coloca en primer plano la inevitable tensión que existe, dentro del constitucionalismo democrático, entre sus compromisos con el autogobierno popular y con el establecimiento de limitaciones sobre las mayorías populares", buscando um equilibrio entre os mesmos.

Discutindo a viabilidade de um diálogo entre o Poder Judiciário e os legisladores, utilizando-se do exemplo da Suprema Corte Canadense, Hogg e Bushel (2014, não paginado) observam que "cuando una decisión judicial está abierta a la revocación, modificación o anulación legislativa, tiene sentido considerar la relación entre la Corte y el órgano legislativo competente como un diálogo". Tem, nesse sentido, a abertura institucional ao debate e a adoção de posturas dialógicas por parte dos atores envolvidos ${ }^{3}$, pressuposto mais do que necessário para o desenvolvimento de um diálogo entre Poderes. Mendes (2014, não paginado), analisando a necessidade de uma teoria da divisão de poderes que acomode as relações que se estabelecem em diferentes momentos, defende "una teoría de la división de poderes que, hasta ciertopunto, plantea una distribución de funciones fluida y no estática".

Reconhece o autor que "no es posible regular constitucionalmente el momento que una institución, y no otra, tendrá la mayor legitimidad social a la hora de tomar las grandes decisiones" (MENDES, 2014, não paginado), sendo o diálogo ferramenta importante para a produção de decisões mais racionais e que não sejam comprometidas por fluxos e influxos ou mesmo relações radicais decorrentes dos arranjos institucionais de cada tempo, o que pode ser avaliado pela fundamentação racional trazida nas decisões. Tushnet (2014) sustenta o que considera como sendo o diálogo ideal, no qual há a criação de uma lei pelo Legislativo, a declaração de inconstitucionalidade da norma pelo Poder Judiciário e, diante dessa, há novo posicionamento do Poder Legislativo - o qual pode ser tanto no sentido de entender que a interpretação inicial é a mais correta ou de aceitar como melhor o posicionamento judicial que aquela se sobrepôs.

A linguagem adotada em termos de diálogo entre Poderes desempenha um

\footnotetext{
Nesse sentido, interessante referir que, em casos como o da utilização da fosfoetanolamina sintética e das diferentes decisões tomadas no âmbito dos três Poderes do Estado, "o caminho percorrido entre Supremo Tribunal Federal, Congresso Nacional e, novamente, Supremo Tribunal Federal demonstra a ausência de um diálogo institucional e a falta de fundamentação entre diferentes decisões - opostas, inclusive - quanto ao mesmo objeto", restando clara a falta de harmonia em diversas decisões judiciais e legislativas (LEAL; MORAES, 2016, p. 49).
}

Revista de Direitos Fundamentais \& Democracia, Curitiba, v. 25, n. 3, p. 32-48, set./dez. 2020 
importante papel na harmonização das relações institucionais, na medida em que "apela a una civilizada y respetuosa resolución de conflito sen momentos marcados por los antagonismos políticos" (GARGARELLA, 2014, não paginado). Essa relação harmônica entre Poderes, voltada a um diálogo consciente, faz com que se estabeleça "uma cadeia de contribuições horizontais que ajudariam a refinar, com a passagem do tempo, boas respostas para questões coletivas. Separação de poderes, nesse sentido, envolveria circularidade e complementaridade infinitas" (MENDES, 2008, p. 15).

Não se quer dizer, com isto, que em nenhum momento se chegará a uma resposta definitiva, mas que há uma abertura a esse processo dialógico que permite que as "últimas respostas" possuam um caráter provisório e permitam que, pela argumentação, se reinterprete o posicionamento antes adotado. Nas palavras de Mendes (2008, p. 97) "essa mudança de perspectiva pretende produzir impacto relevante ao defender que a decisão da corte não é, e não tem como ser, o fim da linha”, mas sim o início de um diálogo entre os Poderes, sustentado pela argumentação.

Sendo assim, essa revisão da decisão judicial, realizada pelo legislador, "debe cumplirciertos requisitos sin los cuales sí cabría la amenaza de una confrontación dialéctica de ida y vuelta entre ramas del gobierno. Uno de ellos sería, por ejemplo, elaborar un informe breve sobre los argumentos esgrimidos" (LINARES, 2014, não paginado). É imprescindível que o diálogo seja pautado em bons argumentos, suficientes para que se sustente a mudança interpretativa. O Suprem Tribunal Federal brasileiro se manifestou, nesse sentido, defendendo a abertura da Corte ao diálogo, como referiu o Ministro Barroso:

\footnotetext{
os diálogos institucionais podem se concretizar por meio de diferentes comportamentos [...]. Verificando que alguma matéria é malversada, mas que a correção depende de atuação do Poder Legislativo, o Supremo Tribunal Federal se manifesta neste sentido, dando ciência ao Legislativo de que há uma mudança a ser feita [...]. A segunda vertente do diálogo institucional, a meu ver, é a devolução da matéria pelo Supremo ao Poder Legislativo [...]. Em vez de dar a última palavra, o Supremo estimula, incentiva o Congresso a prover sobre uma matéria [...]. A terceira e última forma de diálogo institucional, a meu ver, é a superação da jurisprudência, que é precisamente a discussão que nós estamos travando aqui [...]. Devo dizer que a superação de jurisprudência, como é o caso aqui, por aprovação de lei pressupõe que exista mais de uma interpretação constitucional possível e válida para que o Congresso possa optar por uma diferente daquela que o Supremo optou (BRASIL, STF, 2015, p. 89).
}

Esse posicionamento adotado - ao menos discursivamente - por parte de uma 
dor Ministros do mais alto Tribunal brasileiro, em uma primeira referência à postura dialógica, sinaliza para a abertura ao diálogo e para a possibilidade de uma revisão da última palavra em termos de jurisdição. Desse modo, pode-se dizer que, iniciado esse processo, as teorias deliberativas contribuem para a formação de um debate e para o estabelecimento de uma lógica de racionalidade argumentativa que deve permear o diálogo entre Poderes. Há, contudo, a necessidade de uma prática constante nesse sentido, que permita a promoção de consensos, por meio da argumentação, que visem uma melhor interpretação constitucional e também uma maior efetivação em termos de direitos.

\section{CONSIDERAÇÕES FINAIS}

Os modelos de democracia - liberal, representativo, participativo e deliberativo - trazem consigo diferentes características condizentes com as finalidades buscadas por cada um. Não há como se estabelecer um modelo ideia de democracia que seja adaptável a todas as sociedades, nas mais diferentes culturas e que representem os interesses dos cidadãos de forma plena. Isto não faz com que, entretanto, as falhas presentes nas teorias da democracia permitam uma crítica superficial a democracia como um todo.

A democracia, seja qual for o modelo a ser adotado, carrega consigo uma importante carga constitucional e, acima de tudo, busca refletir as necessidades e aspirações da sociedade, sem desconsiderar os direitos dos grupos minoritários. Superou-se a ideia de uma tensão entre direitos fundamentais e democracia, devendo a segunda existir sempre acompanhada da preservação dos primeiros.

As teorias deliberativas, especialmente tratando-se da teoria Habermasiana, pautam-se na produção de consensos, utilizando-se de um procedimento argumentativo e racional, que permita a tomada de decisões mais acertadas. Refletem a necessidade de um debate público sobre assuntos essenciais, tendo sempre como fundamento o conhecimento e a argumentação, buscando a produção de acordos racionais.

Residem nesses pontos as contribuições que as teorias deliberativas podem fornecer as teorias dialógicas, a saber: a) a abertura ao debate racional; b) a necessidade de uma argumentação que denote a relação dialógica e que vise apresentar pontos favoráveis e desfavoráveis à argumentação anterior; c) a importância do estabelecimento de um procedimento legítimo para a produção de 
acordos e d) necessidade de justificação das decisões tomadas, visando a produção de melhores decisões e interpretações. Assim, a lógica deliberativa pode contribuir para uma otimização da aplicação das teorias dialógicas a medida em que preocupase com o procedimento e que sustenta uma lógica argumentativa racional voltada ao debate.

\section{REFERÊNCIAS}

ALVES, Fernando de Brito; SANTOS, Yago Aparecido Oliveira. Democracia e totalitarismo: anotações sobre democracia, separação dos poderes e federalismo. Revista do Direito, Santa Cruz do Sul, v. 1, n. 51, jul. 2017. ISSN 1982-9957. Disponível em: <https://online.unisc.br/seer/index.php/direito/article/view/7897>. Acesso em: 20 nov. 2017. doi:http://dx.doi.org/10.17058/rdunisc.v1i51.7897.

BRANDÃO, Rodrigo. Supremacia judicial versus diálogos constitucionais: a quem cabe a última palavra sobre o sentido da Constituição? Rio de Janeiro: Lumem Juris, 2012.

BRASIL. Supremo Tribunal Federal. Ação Direta de Inconstitucionalidade n. ${ }^{\circ} 5.105$. Rel. Ministro Luiz Fux. Julgada em 01 out. 2015. Disponível em: <http://www.stf.jus.br>. Acessoem: 03 dez. 2017.

DAHL, Robert A. Sobre a democracia. Tradução de Beatriz Sidou. Brasília : Universidade de Brasília, 2001.

FRIEDMAN, Barry. Dialogue and judicial review.The Michigan Law Review Association, Michigan, 91, p. 577-682. 1993.

GUTMANN, Amy; THOMPSON, Dennis. O que significa democracia deliberativa? Revista de Estudos Constitucionais (RBEC), Belo Horizonte, v. 1, n. 1, jan./mar. 2007. Disponível em: file:///G:/GUTMAN\%20e\%20THOMPSON\%20\%200\%20que\%20significa\%20a\%20democracia\%20deliberativa.pdf. Acesso em: 11 dez. 2017.

HABERMAS, Jürgen. A inclusão do outro. $3^{\text {a }}$ ed. Trad. George Sperber, Paulo AstorSoethe e Milton Camargo Mota. São Paulo: Loyola, 2007.

HELD, David. Modelos de democracia. Belo Horizonte: Paidéia, 1987.

HOGG, P. W.; BUSHELL, A. A. El diálogo de la Carta entre los Tribunales y las Legislaturas. In: GARGARELLA, Roberto (Org.). Por una justicia dialógica: el Poder Judicial como promotor de la deliberación democrática. Buenos Aires: SigloVeintiuno, 2014. Não paginado. Epub.

LATINNO. Desenvolvido por Thamy Pogrebinschi. 2015-2018. Inovações para a Democracia na América Latina. Disponível em: $<$ https://www.latinno.net/pt/country/brazil/ >. Acesso em: 30 ago. 2018.

LEAL, MôniaClarissaHennig; MORAES, Maria Valentina de. O princípio da separação 
de poderes e a ponderação de competências: uma análise crítica a partir da decisão sobre a fosfoetanolamina. Revista do Direito, Santa Cruz do Sul, v. 3, n. 50, p. 34-52, set. 2016. ISSN 1982-9957. Disponível

em:<https://online.unisc.br/seer/index.php/direito/article/view/8464>. Acesso em: 07 dez. 2017. doi:http://dx.doi.org/10.17058/rdunisc.v3i50.8464.

LEAL, Rogério Gesta. Demarcações conceituais preliminares da democracia deliberativa : matrizes Habermasianas. In:____ (org). A democracia deliberativa como nova matriz de gestão pública [recurso eletrônico]: alguns estudos de casos. Santa Cruz do Sul: EDUNISC, 2011.

LINARES, Sebastián. Justicia dialógica interinstitucional: de lege ferenda y de lege lata. In: GARGARELLA, Roberto (Org.). Por una justicia dialógica: el Poder Judicial como promotor de la deliberación democrática. Buenos Aires: SigloVeintiuno, 2014. Não paginado. Epub.

MÁRMOL, José Luis Martí. Democracia y deliberación. Una reconstrucción del modelo de Jon Elster. Revista Estudios Políticos (Nueva Época), n. 1, jul/set., 2001.

Disponívelem:

http://www.cepc.gob.es/publicaciones/revistas/revistaselectronicas?IDR=3\&IDN=270\&I DA=17377. Acesso em: 22 nov. 2017.

MENDES, Conrado Hübner. Direitos fundamentais, separação de poderes e deliberação. São Paulo, 2008. 219 f. Tese: Doutorado em Ciência Política. Faculdade de Filosofia, Letras e Ciências Humanas, Universidade de São Paulo.

MENDES, Conrado Hübner. Una división de poderes deliberativa: entre el diálogo y la última palabra. In: GARGARELLA, Roberto (Org.). Por una justicia dialógica: el Poder Judicial como promotor de la deliberación democrática. 1. ed. Buenos Aires: Siglo Veintiuno, 2014. Não paginado. Epub.

MILL, John Stuart. Sobre la liberdad. Madrid: Alianza, 1986.

MOUFFE, Chantal. La-Paradoja Democratica. Barcelona: Gedisa, 2003.

MÜLLER, Fredrich. Quem é o povo?. 7. ed. São Paulo: Revista dos Tribunais, 2013.

NINO, Carlos Santiago. La constitución de la democracia deliberativa.Barcelona: Gedisa, 1997.

NOVAIS, Jorge Reis. Direitos fundamentais: trunfos contra a maioria. Lisboa: Coimbra Editora, 2006.

PATEMAN, Carole. Participação e teorias da democracia. Tradução de Luiz Paulo Rouanet. Rio de Janeiro: Paz e terra, 1992.

SCHUMPETER, Joshep. Capitalismo, Socialismo e Democracia. Rio de Janeiro: Fundo de Cultura, 1961.

SOUZA, Cristiane Fernandes de; SOUZA, Paulo de Tarso Fernandes de. Direito e democracia - o significado das leis e do legislativo na teoria da democracia. Revista do 
Direito, Santa Cruz do Sul, v. 1, n. 51, jul. 2017. ISSN 1982-9957. Disponível em: <https://online.unisc.br/seer/index.php/direito/article/view/7784>. Acesso em: 20 nov. 2017. doi:http://dx.doi.org/10.17058/rdunisc.v1i51.7784.

TUSHNET, Mark. Revisión judicial dialógica. In: GARGARELLA, Roberto (Org.). Por una justicia dialógica: el Poder Judicial como promotor de la deliberación democrática. Buenos Aires: SigloVeintiuno, 2014. Não paginado. Epub

Recebido em 13/03/2018

Aprovado em 23/08/2018

Received in 13/03/2018

Approved in 23/08/2018 